\title{
Influence of Crown/Implant Ratio on Marginal Bone Loss: A Systematic Review
}

\author{
Carlos Garaicoa-Pazmiño, * Fernando Suárez-López del Amo, * Alberto Monje, * Andrés Catena, ${ }^{\dagger}$ \\ Inmaculada Ortega-Oller, ${ }^{\ddagger}$ Pablo Galindo-Moreno, ${ }^{\ddagger}$ and Hom-Lay Wang*
}

Background: With the increased use of short dental implants $(<10 \mathrm{~mm})$, a high crown/implant $(\mathrm{C} / \mathrm{I})$ ratio has become a common finding. However, the effect of the $\mathrm{C} / \mathrm{I}$ ratio on the marginal bone loss (MBL) has not yet been examined extensively. Hence, the aim of the present systematic review is to explore the influence of the $\mathrm{C} / \mathrm{I}$ ratio on the success rate and MBL of dental implants.

Methods: Three electronic databases (PubMed, Ovid MEDLINE, and Cochrane Central) and a manual search for human trials with a minimal follow-up of 6 months are used for the present study. A statistical analysis of the influence of the $\mathrm{C} / \mathrm{I}$ ratio was performed on the peri-implant $\mathrm{MBL}$ while considering follow-up period, type of implants, implant connection, and technical and biologic complications.

Results: One hundred ninety-six potential articles were identified on the selected databases. Only 57 articles were selected for full-text evaluation. According to the inclusion criteria, a total of 13 articles were included in this systematic review. A significant negative association between the $\mathrm{C} / \mathrm{I}$ ratio and the MBL was found $(P=0.012)$. However, no statistically significant difference was found $(P>0.15)$ for potential effects regarding the observation period, the type of implant connection, or between both methods of evaluating the $\mathrm{C} / \mathrm{I}$ ratio.

Conclusions: Within the limitations of the present study, the $\mathrm{C} / \mathrm{I}$ ratio of implant-supported restorations has an effect on peri-implant marginal bone level. Within the range of $0.6 / 1$ to $2.36 / 1$, the higher the $\mathrm{C} / \mathrm{I}$ ratio, the less the periimplant MBL. J Periodontol 2014;85:1214-1221.

\section{KEY WORDS}

Dental implant-abutment design; design implantation; dental implants; dental prosthesis, implant-supported.

\footnotetext{
* Graduate Periodontics, Department of Periodontics and Oral Medicine, University of Michigan School of Dentistry, Ann Arbor, MI.

$\uparrow$ Department of Experimental Psychology, University of Granada, Granada, Spain.

‡ Department of Oral Surgery and Implant Dentistry, University of Granada.
}

Tooth loss is often associated with compromised esthetics, function, and subsequent alveolar bone resorption that ultimately may compromise the final rehabilitation procedure. ${ }^{1,2}$ Bone resorption presents several challenges, including the prevention of appropriate implant position or even the absence of sufficient bone for implant placement. ${ }^{3}$ Various procedures are available currently to overcome these limitations. The use of short dental implants $(<10 \mathrm{~mm})$ represents a reliable alternative option. ${ }^{4}$ The benefits of using a shorter implant include no need for advanced bone grafting and, consequently, lower risk of complications and expenses, which greatly increases a patient's acceptance. ${ }^{5}$ As proof of their effectiveness, short implants have shown survival rates similar to standard $(\geq 10$ $\mathrm{mm}$ ) implants, ${ }^{6,7}$ regardless of their length and width. ${ }^{8}$ However, a recent meta-analysis demonstrated that, even with a similar long-term survival rate, shorter implants failed 2.5 years earlier than the standard ones. ${ }^{7}$

Nevertheless, the use of short dental implants is not exempt from clinically challenging situations. An increased crown/implant (C/I) ratio is usually found when $<10-\mathrm{mm}$ implants are placed compared to the normal crown/root $(\mathrm{C} / \mathrm{R})$ ratio associated with healthy dentition. Theoretically, the $\mathrm{C} / \mathrm{R}$ ratio is the relationship between the length 
of the crown and the length of the root, taking the cemento-enamel junction as the fixed point separating both. Conversely, the clinical $C / R$ ratio is the physical relationship between the portion of the tooth located above the alveolar bone compared to the portion embedded into the alveolar bone, as seen radiographically. ${ }^{9}$

Accordingly, the $\mathrm{C} / \mathrm{I}$ ratio can be defined anatomically, which takes the implant shoulder as the boundary between the crown and the implant, and clinically, which takes the bone level as the boundary separating crown and implant (Fig. 1). Over the years, several publications reported the $\mathrm{C} / \mathrm{I}$ ratios of their implant-supported prosthesis. ${ }^{10-12}$ However, although some authors reported the anatomic C/I ratio, ${ }^{13,14}$ others showed the clinical $\mathrm{C} / \mathrm{I}$ ratio. ${ }^{15,16}$ Although the clinical $\mathrm{C} / \mathrm{I}$ ratio seems to describe a more realistic biomechanical scenario, ${ }^{17}$ the anatomic $\mathrm{C} / \mathrm{I}$ ratio is most commonly found in the literature.

The importance of the $\mathrm{C} / \mathrm{I}$ ratio relies on the theory that unfavorable occlusal forces, including non-axial and overload, represent one possible explanation for biologic and technical complications. ${ }^{17,18}$ Higher $\mathrm{C} / \mathrm{I}$ ratios display a form of non-axial force in which the crown acts as a lever arm that creates a bending moment, transferring stress to the peri-implant crestal bone. ${ }^{19}$ Technical complications ${ }^{20}$ and/or crestal bone $\operatorname{loss}^{21}$ may result from this occlusal stress. As a result, C/I ratios from 0.5 to 1 were proposed to avoid crestal bone loss. ${ }^{22}$

Literature exploring the influence of the C/I ratio on the success rate and implant marginal bone loss (MBL) is heterogeneous, with a limited number of studies reporting great variability regarding their findings. Although some studies

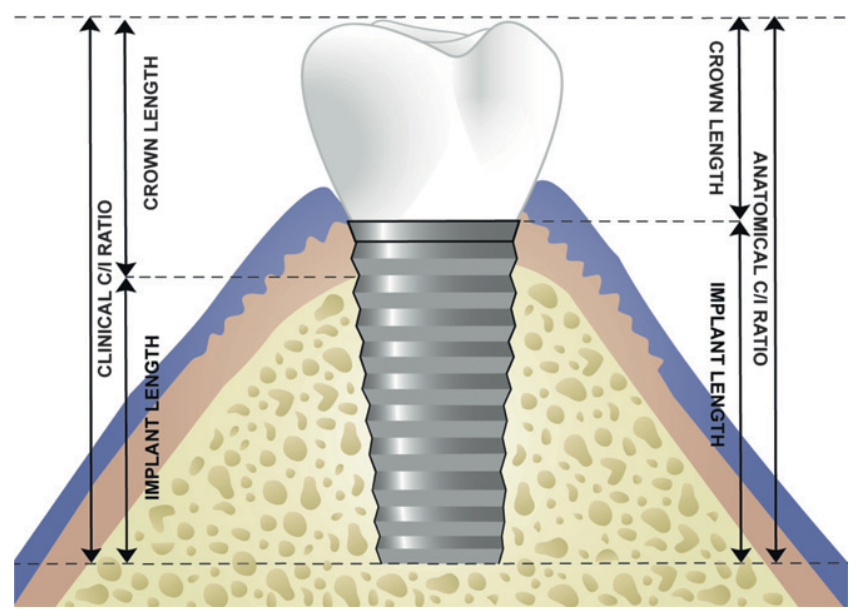

Figure I.

Representation of the anatomic and clinical C/l ratio. failed to show a correlation between the $\mathrm{C} / \mathrm{I}$ ratio and MBL, ${ }^{10,13,17}$ others reported higher amounts of MBL with increased C/I ratios. ${ }^{12}$ Surprisingly, some studies even reported an inverse relationship between the C/I ratio and MBL, finding better results with higher ratios. ${ }^{15,16}$ In addition, there is limited literature reporting the incidence of biologic and/or technical complications associated with this topic.

Hence, the aim of the present review is to explore the influence of the $\mathrm{C} / \mathrm{I}$ ratio on the success and $\mathrm{MBL}$ of dental implants.

\section{MATERIALS AND METHODS}

Three electronic databases, including PubMed, Ovid (MEDLINE), and Cochrane Central, were used to find relevant studies. Articles restricted to the English language were considered without any time limitation. The search was conducted from February 2013 through March 2013 by two examiners (FS and CG-P). The search terms used included the following: ("Jaw, edentulous" [mh] OR "Alveolar process" [mh] OR "Dental implants, single-tooth"[mh] OR "Dental implantation"[mh] OR "Dental implants" [mh] OR "Dental prosthesis design" [mh] OR "Crown-toimplant ratio"[tiab]) AND ("short"[tiab] OR "restoration"[tiab] OR "bone loss"[tiab]), where mh and tiab represented $\mathrm{MeSH}$ term and title or abstract, respectively.

Furthermore, references in the included papers were identified and reviewed by their titles and abstracts. A supplementary manual search in dental journals up to February 2013 was performed, including the following: 1) Journal of Clinical Periodontology; 2) Journal of Oral and Maxillofacial Surgery; 3) Journal of Periodontology; 4) The International Journal of Periodontics \& Restorative Dentistry; 5) International Journal of Prosthodontics; 6) European Journal of Oral Implantology; 7) Journal of Oral and Maxillofacial Implants; 8) Journal of Oral Implantology; 9) Implant Dentistry; 10) Clinical Implant Dentistry and Related Research; 11) Clinical Oral Implants Research; 12) Journal of Prosthetic Dentistry; 13) International Journal of Oral and Maxillofacial Surgery; and 14) Journal of Dental Research.

For this systematic review, only articles fulfilling the following selection criteria were considered: human clinical trials, either prospective or retrospective, that reported the mean $\mathrm{C} / \mathrm{I}$ ratio and $\mathrm{MBL}$ with at least 6-month follow-up. In addition, these papers had to include how the $\mathrm{C} / \mathrm{I}$ ratio was measured. Conversely, animal studies, finite element analysis, case reports/series, review articles, or clinical trials with less than five participants and insufficient followup time were excluded. 
The relationship between the $\mathrm{C} / \mathrm{I}$ ratio and the $\mathrm{MBL}$ was evaluated while considering the observation period, the type of implant connection, and between both types of measurement for the C/I ratio for any additional effects. No additional interpretation for timing of restoration was made because of the fact that, after analyzing current evidence, different protocols for time of restoration delivery have shown no effect on MBL. ${ }^{23}$

Publication bias was assessed qualitatively by judging the selection and comparability of the study groups and the ascertainment of the exposure or outcome of interest for the included studies. ${ }^{24}$ Qualitative analysis pertained to the criteria for determining the quality of the research. For the statistical analysis, it was assumed that heterogeneity was present in the studies' datasets.

The potential relationship between the $\mathrm{C} / \mathrm{I}$ ratio and MBL was determined using multivariate randomeffects metaregression, ${ }^{25}$ in which the covariates include the $\mathrm{C} / \mathrm{I}$ ratio, the observation period, the type of connection, and the type of measure (anatomic/clinical). A $P$ value of 0.05 was set as the significance threshold. The Newcastle-Ottawa scale (NOS) was used to assess the quality of such studies for a proper understanding of nonrandomized studies. ${ }^{26}$

PubMed, Ovid (MEDLINE) and Cochrane Central databases searched

Limits: English-language articles only

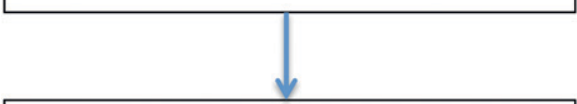

197 Potential articles identified through database searching

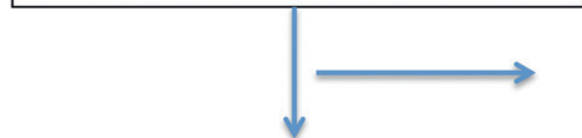

Full texts of these articles were obtained: $\mathrm{N}=57$

13 Articles included in this review
140 Articles excluded based on the titles/abstracts

44 Articles excluded based on the full-text evaluation:

Four literature reviews One systematic review Two in vitro

30 not evaluating $\mathrm{C} / \mathrm{I}$ ratio

Two did not report mean $\mathrm{C} / \mathrm{I}$ ratio

Three did not report MBL

Two in a different language
Figure 2.

Flowchart of the screening process.

\section{RESULTS}

During the screening process, 197 potential articles were identified, and 140 were excluded based on their titles and abstracts as represented in the flowchart (Fig. 2). A full-text version of the 57 remaining articles was obtained for evaluation. Forty-four of the articles were excluded from the present study by not plishing the inclusion criteria as depicted in 2. Only 13 articles were included in this

The multivariate random-effects metaregression yielded a significant association between the $\mathrm{C} / \mathrm{I}$ ratio and the MBL $(z=-2.52, P=0.012,95 \%$ confidence interval $=-2.09$ to 0.26 as represented in Fig. 3).

Table 1 summarizes the characteristics of the included articles. The results from the present study fail to show any statistically significant difference $(P>0.15)$ favoring any potential effect regarding the observation period, the type of the implant connection, or the types of measurement for the $\mathrm{C} / \mathrm{I}$ ratio (clinical or anatomic).

All the articles included in the present systematic review are prospective or retrospective human clinical trials with the clear aim of studying survival of dental implants and assessing the influence of the $\mathrm{C} / \mathrm{I}$ ratio on it. Because no randomized clinical trial was included, the NOS was used to assess the quality of all the included studies for a proper understanding of nonrandomized studies. ${ }^{26}$ This was performed by a single, masked examiner (AM). The mean $\pm S D$ NOS for the studies included in the present systematic review is $6.78 \pm 2.01$, displaying what the authors of this study determined an acceptable level of evidence of $\mathrm{C} / \mathrm{I}$ influence on implant survival in the included studies.

\section{DISCUSSION}

Centripetal and centrifugal bone loss after tooth extraction is often associated with inadequate bone quantity for proper threedimensional implant placement. ${ }^{1}$ To overcome the bone resorption problem, bone augmentation procedures are often recommended to create a better environment for implant osseointegration. Nonetheless, this might lead to intraoperative and postoperative complications (i.e., excessive bleeding 


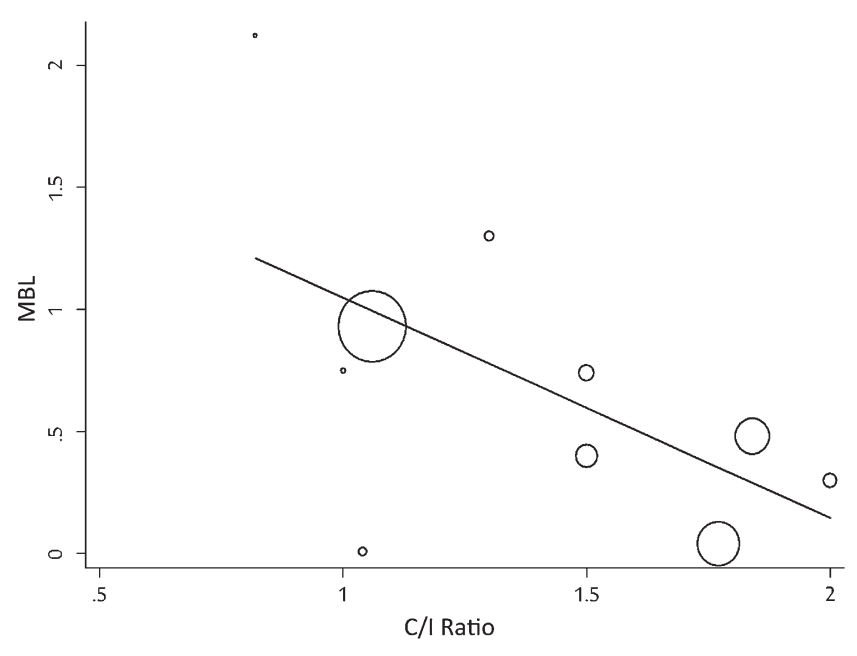

Figure 3.

Association between the $\mathrm{C} / \mathrm{l}$ ratio and $\mathrm{MBL}$ according to the randomeffects metaregression expressed in proportion and millimeters, respectively. The area of each circle is inversely proportional to the variance of the $M B L$ estimate.

or morbidity of the donor site). Furthermore, it is important to bear in mind that cost and time would increase, thus decreasing the patient's overall satisfaction and acceptance of treatment. Therefore, the use of narrower and shorter implants was thought to minimize drawbacks. $6,7,34,35$ Consequently, when $<10$-mm implants are placed in partially dentate patients, a high C/I ratio might be displayed. In this situation, short implants are often under bending moments because of a large $\mathrm{C} / \mathrm{I}$ ratio. It could thus be hypothesized that an increase in MBL is caused by an increased C/I ratio.

Blanes ${ }^{17}$ demonstrated in a previous systematic review that an increased $\mathrm{C} / \mathrm{I}$ ratio did not have repercussions on MBL. However, because of the dearth of available data when performed, conclusive results could not be drawn. Conversely, the present findings confirm that a high $\mathrm{C} / \mathrm{I}$ ratio does not contribute to more peri-implant MBL.

The loss of supporting bone around dental implants in function is reported as one of the major complications for implant failure. ${ }^{36,37}$ Biologic and mechanical complications are capable of inducing disturbances of the supporting tissues around implants, including peri-implantitis and perimucositis. ${ }^{38}$ Although potential host risk factors were identified and strongly associated with peri-implant diseases, ${ }^{39}$ the assessment of the biomechanical properties of implant-supported restorations remains a challenge.

Rieger et al. ${ }^{19}$ demonstrated that high levels of stress during bending moments are located around the neck and apex of the implant. In addition, the authors observed a distribution of these bending forces along the axis of the implant fixture. These outcomes may suggest that higher $\mathrm{C} / \mathrm{I}$ ratios may create more stress around the implant shoulders and induce bone loss that could endanger the long-term success rates. ${ }^{19}$ Nevertheless, previous animal studies failed to demonstrate that stress concentrations around implants could lead to bone resorption. ${ }^{40,41}$ Despite such concerns, implants with an increased C/I ratio can still achieve a long-term survival rate as long as the occlusion and parafunctional habits are controlled. ${ }^{13}$

It has been suggested that occlusal overload should be considered as a possible risk factor for peri-implant tissue breakdown and a primary cause for early implant failure. ${ }^{42}$ In a systematic review, Chambrone et al. ${ }^{43}$ were not able to determine whether an excessive occlusal load has a negative effect on osseointegration. One possible explanation is the lack of information regarding prosthetic factors. As observed in the present study, only some of the included studies mention in detail the implant systems used, opposing arch, and type of restoration, factors which may facilitate a more accurate analysis. Furthermore, splinting implants aims to reduce the amount of force applied over a single implant to avoid excessive occlusal forces, but no clear distinction among the included studies was found to establish a difference between groups and their influence on the MBL.

The present results report an inverse correlation between the $\mathrm{C} / \mathrm{I}$ ratios and the MBL $(P=0.012)$. In concordance with a previous systematic review, ${ }^{17}$ the clinical application of these findings suggests that shorter implants $(<10 \mathrm{~mm})$ supporting larger implant-supported restorations may have less MBL compared to standard implants $(\geq 10 \mathrm{~mm})$. Despite the current biomechanical considerations, every clinical scenario should be analyzed properly. Moreover, a correlation of the present study was found with previous results that showed that MBL around short dental implants $(<10 \mathrm{~mm})$ is similar when compared to standard longer implants. ${ }^{44}$ Hence, together with this fact, it is understandable to think that MBL is independent of implant length. However, it is important to bear in mind that, because MBL is the major predictor for implant success, length will play a crucial role in failure timing. This assumption is in accordance with Monje et al. ${ }^{7}$ who found that short implants, as defined for implants $<10 \mathrm{~mm}$, fail 2.5 years before standard implants $(\geq 10 \mathrm{~mm})$. Furthermore, the present findings demonstrate that short dental implants with a high $\mathrm{C} / \mathrm{I}$ ratio could be considered as a possible treatment option without major concern for the MBL. Controversially, Bayraktar et al. ${ }^{45}$ in a finite element analysis reported that the 


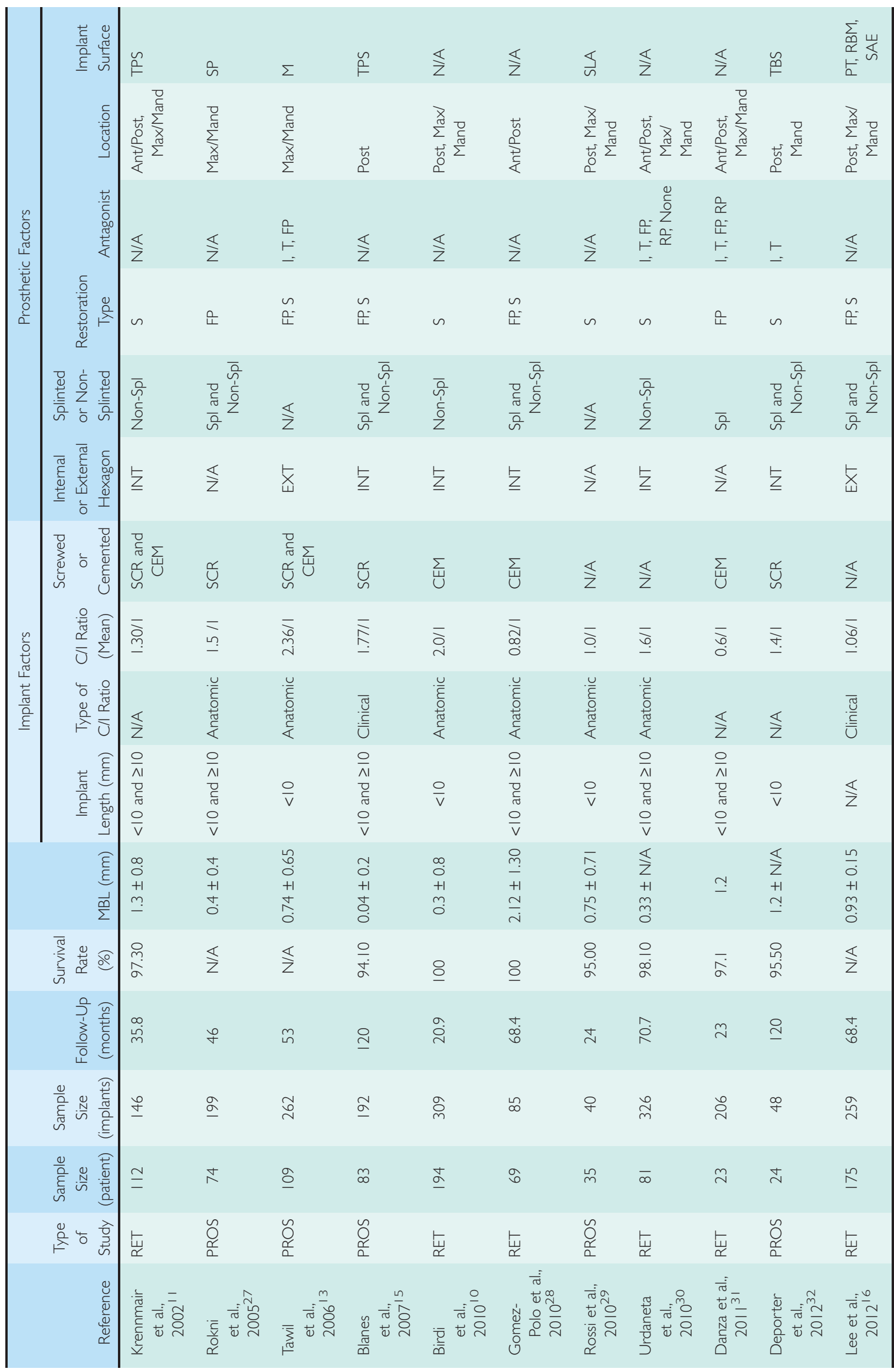




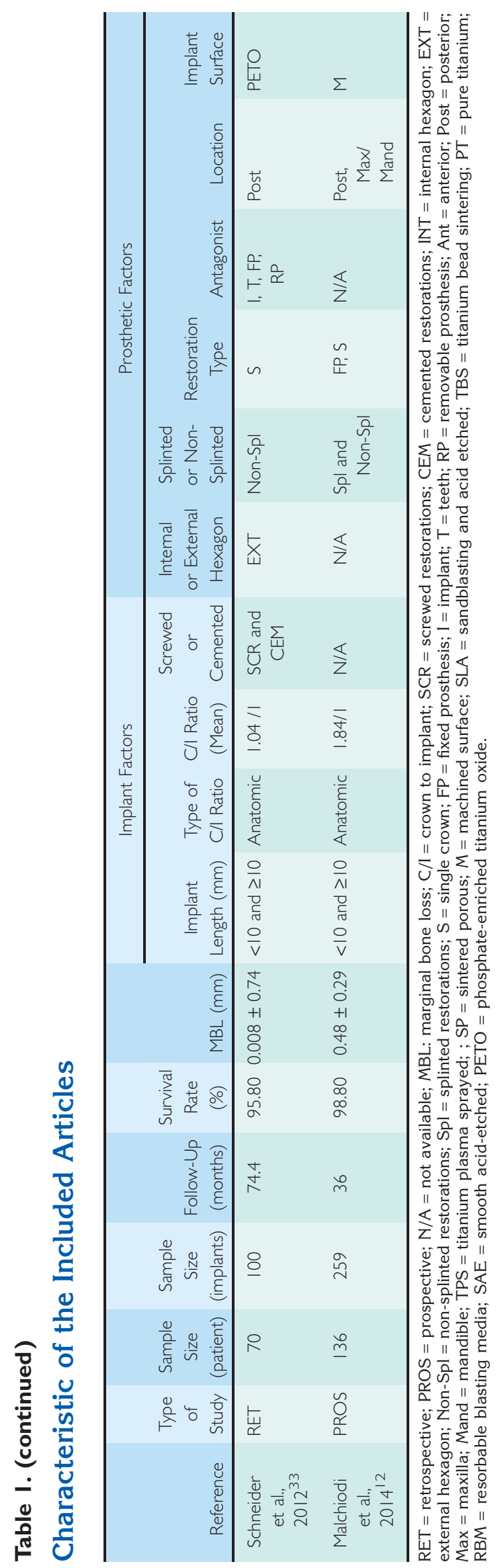

implant length had less influence on the MBL than the implant diameter and targeted the crown height as the main factor affecting the surrounding hard tissues. Moreover, if accepting that MBL is the main predictor in implant long-term success, a recent meta-analysis showed the null hypothesis that implant diameter matters for short-implant success rate. ${ }^{8}$ Consequently, both short and standard implants must be meticulously maintained to minimize MBL and increase the longterm survival rate. ${ }^{7}$

Conversely, several publications described that increased C/I ratios may not be considered a risk factor for implant failure. Tawil et al. ${ }^{13}$ failed to establish a correlation between MBL and numerous variables, including $\mathrm{C} / \mathrm{I}$ ratio, the presence of cantilever, and the occlusal table and pattern. Similarly, Birdi et al. ${ }^{10}$ in a retrospective cohort study evaluating 309 implants found no association between the $\mathrm{C} / \mathrm{I}$ ratio and MBL. More recently, Okada et al. ${ }^{46}$ showed that implants with high $\mathrm{C} / \mathrm{I}$ ratios had an increased bone remodeling activity, but MBL did not differ from implants with similar and lower $\mathrm{C} / \mathrm{I}$ ratios. In addition, the authors suggested that proper plaque control might provide an additional effect for implant stability.

Numerous publications mentioned the $\mathrm{C} / \mathrm{I}$ ratios of their implant-supported prosthesis. ${ }^{10-12}$ However, the measurement of the $\mathrm{C} / \mathrm{I}$ ratio has been approached from different perspectives because of the absence of a consensus definition of $\mathrm{C} / \mathrm{I}$ ratio. ${ }^{17}$ Commonly, some authors reported the anatomic C/I ratio,13,14,29 whereas others showed the clinical C/I ratio, ${ }^{15,16}$ which it has been described to represent a more realistic scenario. ${ }^{17}$ The results from the present study do not support any potential effect for either type of measurement of the $\mathrm{C} / \mathrm{I}$ ratio.

\section{CONCLUSIONS}

Conflicting and limited information on the $\mathrm{C} / \mathrm{I}$ ratio was found in the literature. When analyzing the results from the present study, caution should be taken when extrapolating the conclusions to clinical scenarios. Most of the included articles lacked information to determine the reliability of the restored implants. Although throughout the years multiple studies evaluated the mechanical consideration of implant therapy, this study fails to demonstrate that high C/I ratios may play a role in promoting MBL. Nonetheless, biomechanics and occlusal considerations have been demonstrated to be of paramount importance. Within the limitations of the present study, it can be concluded that a high C/I ratio of implant-supported restorations may provide a protective effect on peri-implant marginal bone level. 


\section{ACKNOWLEDGMENTS}

This study was partially supported by the University of Michigan Periodontal Graduate Student Research Fund. The authors thank Ms. Claire Jones, Multimedia Designer of the Dental Informatics Department at the University of Michigan, Ann Arbor, Michigan, for the design of the illustrations used. The authors report no conflicts of interest related to this study.

\section{REFERENCES}

1. Schropp L, Wenzel A, Kostopoulos L, Karring T. Bone healing and soft tissue contour changes following single-tooth extraction: A clinical and radiographic 12-month prospective study. Int J Periodontics Restorative Dent 2003;23:313-323.

2. Schneider R. Prosthetic concerns about atrophic alveolar ridges. Postgrad Dent 1999;6:3-7.

3. Esposito M, Grusovin MG, Felice P, Karatzopoulos G, Worthington HV, Coulthard P. The efficacy of horizontal and vertical bone augmentation procedures for dental implants - A Cochrane systematic review. Eur J Oral Implantology 2009;2:167-184.

4. Atieh MA, Zadeh H, Stanford CM, Cooper LF. Survival of short dental implants for treatment of posterior partial edentulism: A systematic review. Int $J$ Oral Maxillofac Implants 2012;27:1323-1331.

5. Esposito M, Cannizzaro G, Soardi E, et al. Posterior atrophic jaws rehabilitated with prostheses supported by $6 \mathrm{~mm}$-long, $4 \mathrm{~mm}$-wide implants or by longer implants in augmented bone. Preliminary results from a pilot randomised controlled trial. Eur J Oral Implantology 2012;5:19-33.

6. Pommer B, Frantal S, Willer J, Posch M, Watzek G, Tepper G. Impact of dental implant length on early failure rates: A meta-analysis of observational studies. $J$ Clin Periodontol 2011;38:856-863.

7. Monje A, Chan HL, Fu JH, Suarez F, Galindo-Moreno P, Wang HL. Are short dental implants $(<10 \mathrm{~mm})$ effective? A meta-analysis on prospective clinical trials. J Periodontol 2013;84:895-904.

8. Monje A, Fu JH, Chan HL, et al. Do implant length and width matter for short dental implants $(6-9 \mathrm{~mm})$ ? A meta-analysis of prospective studies. J Periodontol 2013;84:1783-1791.

9. [No authors listed]. The glossary of prosthodontic terms. J Prosthet Dent 2005;94:10-92.

10. Birdi H, Schulte J, Kovacs A, Weed M, Chuang SK. Crown-to-implant ratios of short-length implants. J Oral Implantol 2010;36:425-433.

11. Krennmair G, Schmidinger S, Waldenberger O. Singletooth replacement with the Frialit-2 system: A retrospective clinical analysis of 146 implants. Int $J$ Oral Maxillofac Implants 2002;17:78-85.

12. Malchiodi L, Cucchi A, Ghensi P, Consonni D, Nocini $\mathrm{PF}$. Influence of crown-implant ratio on implant success rates and crestal bone levels: A 36-month follow-up prospective study. Clin Oral Implants Res 25:240251.

13. Tawil G, Aboujaoude N, Younan R. Influence of prosthetic parameters on the survival and complication rates of short implants. Int $J$ Oral Maxillofac Implants 2006;21:275-282.

14. Schulte J, Flores AM, Weed M. Crown-to-implant ratios of single tooth implant-supported restorations. J Prosthet Dent 2007;98:1-5.
15. Blanes RJ, Bernard JP, Blanes ZM, Belser UC. A 10-year prospective study of ITI dental implants placed in the posterior region. II: Influence of the crown-to-implant ratio and different prosthetic treatment modalities on crestal bone loss. Clin Oral Implants Res 2007;18:707-714.

16. Lee KJ, Kim YG, Park JW, Lee JM, Suh JY. Influence of crown-to-implant ratio on periimplant marginal bone loss in the posterior region: A five-year retrospective study. J Periodontal Implant Sci 2012;42:231-236.

17. Blanes RJ. To what extent does the crown-implant ratio affect the survival and complications of implant-supported reconstructions? A systematic review. Clin Oral Implants Res 2009;20(Suppl. 4):67-72.

18. Isidor F. Influence of forces on peri-implant bone. Clin Oral Implants Res 2006;17(Suppl. 2):8-18.

19. Rieger MR, Mayberry M, Brose MO. Finite element analysis of six endosseous implants. $J$ Prosthet Dent 1990;63:671-676.

20. Rangert B, Krogh PH, Langer B, Van Roekel N. Bending overload and implant fracture: A retrospective clinical analysis. Int $J$ Oral Maxillofac Implants 1995;10:326334.

21. Misch CE, Suzuki JB, Misch-Dietsh FM, Bidez MW. A positive correlation between occlusal trauma and periimplant bone loss: Literature support. Implant Dent 2005; 14:108-116.

22. Glantz PO, Nilner K. Biomechanical aspects of prosthetic implant-borne reconstructions. Periodontol 2000 1998; 17:119-124.

23. Suarez F, Chan HL, Monje A, Galindo-Moreno P, Wang HL. Effect of the timing of restoration on implant marginal bone loss: A systematic review. J Periodontol 2013;84:159-169.

24. Wells GA, Shea B, O'Connell D, Peterson J, Welch V, Losos M. The Newcastle-Ottawa Scale (NOS) for assessing the quality of non-randomized studies in metaanalyses. Available at: http://www.ohri.ca/programs/ clinical_epidemiology/oxford.htm. Accessed October 4, 2013.

25. Thompson SG, Higgins JP. How should meta-regression analyses be undertaken and interpreted? Stat Med 2002;21:1559-1573.

26. Stang A. Critical evaluation of the Newcastle-Ottawa scale for the assessment of the quality of non-randomized studies in meta-analyses. Eur $J$ Epidemiol 2010;25: 603-605.

27. Rokni S, Todescan R, Watson P, Pharoah M, Adegbembo AO, Deporter D. An assessment of crown-to-root ratios with short sintered porous-surfaced implants supporting prostheses in partially edentulous patients. Int $J$ Oral Maxillofac Implants 2005;20:69-76.

28. Gomez-Polo M, Bartens F, Sala L, Tamini F, Celemin A, Del Rio J. The correlation between crown-implant ratios and marginal bone resorption: A preliminary clinical study. Int J Prosthodont 2010;23:33-37.

29. Rossi F, Ricci E, Marchetti C, Lang NP, Botticelli D. Early loading of single crowns supported by $6-\mathrm{mm}$ long implants with a moderately rough surface: A prospective 2-year follow-up cohort study. Clin Oral Implants Res 2010;21:937-943.

30. Urdaneta RA, Rodriguez S, McNeil DC, Weed M, Chuang SK. The effect of increased crown-to-implant ratio on single-tooth locking-taper implants. Int J Oral Maxillofac Implants 2010;25:729-743.

31. Danza M, Grecchi F, Zollino I, Casadio C, Carinci F. Spiral implants bearing full-arch rehabilitation: Analysis of clinical outcome. J Oral Implantol 2011;37:447-455. 
32. Deporter DA, Kermalli J, Todescan R, Atenafu E. Performance of sintered, porous-surfaced, press-fit implants after 10 years of function in the partially edentulous posterior mandible. Int $J$ Periodontics $R e$ storative Dent 2012;32:563-570.

33. Schneider $\mathrm{D}$, Witt L, Hämmerle $\mathrm{CH}$. Influence of the crown-to-implant length ratio on the clinical performance of implants supporting single crown restorations: A cross-sectional retrospective 5-year investigation. Clin Oral Implants Res 2012;23:169-174.

34. Sun HL, Huang C, Wu YR, Shi B. Failure rates of short $(\leq 10 \mathrm{~mm}$ ) dental implants and factors influencing their failure: A systematic review. Int $J$ Oral Maxillofac Implants 2011;26:816-825.

35. Ortega-Oller I, Suarez F, Galindo-Moreno P, et al. The influence of implant diameter upon its survival: A metaanalysis based on prospective clinical trials. $J$ Periodontol 2014;85:569-80.

36. Zitzmann NU, Berglundh T. Definition and prevalence of peri-implant diseases. J Clin Periodontol 2008;35 (Suppl. 8):286-291.

37. Roos-Jansåker AM, Lindahl C, Renvert H, Renvert S. Nine- to fourteen-year follow-up of implant treatment. Part II: Presence of peri-implant lesions. J Clin Periodontol 2006;33:290-295.

38. Berglundh T, Persson L, Klinge B. A systematic review of the incidence of biological and technical complications in implant dentistry reported in prospective longitudinal studies of at least 5 years. J Clin Periodontol 2002;29(Suppl. 3):197-212; discussion 232233.

39. Heitz-Mayfield LJ. Peri-implant diseases: Diagnosis and risk indicators. J Clin Periodontol 2008;35(Suppl. 8): 292-304.

40. Kozlovsky A, Tal H, Laufer BZ, et al. Impact of implant overloading on the peri-implant bone in inflamed and non-inflamed peri-implant mucosa. Clin Oral Implants Res 2007;18:601-610.

41. Heitz-Mayfield LJ, Schmid B, Weigel C, et al. Does excessive occlusal load affect osseointegration? An experimental study in the dog. Clin Oral Implants Res 2004;15:259-268

42. Quirynen M, Naert I, van Steenberghe D. Fixture design and overload influence marginal bone loss and fixture success in the Brånemark system. Clin Oral Implants Res 1992;3:104-111.

43. Chambrone L, Chambrone LA, Lima LA. Effects of occlusal overload on peri-implant tissue health: A systematic review of animal-model studies. J Periodontol 2010;81:1367-1378.

44. Monje A, Suarez F, Galindo-Moreno P, García-Nogales A, Fu JH, Wang HL. A systematic review on marginal bone loss around short dental implants $(<10 \mathrm{~mm})$ for implant-supported fixed prostheses. Clin Oral Implants Res. doi:10.1111/clr.12236.

45. Bayraktar M, Gultekin BA, Yalcin S, Mijiritsky E. Effect of crown to implant ratio and implant dimensions on periimplant stress of splinted implant-supported crowns: A finite element analysis. Implant Dent 2013; 22:406-413.

46. Okada S, Koretake K, Miyamoto Y, Oue H, Akagawa Y. Increased crown-to-implant ratio may not be a risk factor for dental implant failure under appropriate plaque control. PLoS One 2013;8:e63992.

Correspondence: Dr. Hom-Lay Wang, Department of Periodontics and Oral Medicine, University of Michigan School of Dentistry, 1011 N. University Ave., Ann Arbor, MI 48109-1078. Fax: 734/936-0374; e-mail: homlay@umich.edu.

Submitted October 15, 2013; accepted for publication December 30, 2013. 